\title{
The risk and nature of flares in juvenile idiopathic arthritis: results from the reACCh-Out cohort
}

\author{
Jaime Guzman ${ }^{1 *}$, Kiem Oen ${ }^{2}$, Adam M Huber ${ }^{3}$, Gilles Boire ${ }^{4}$, Karen Watanabe Duffy ${ }^{5}$, Roberta Berard ${ }^{6}$, \\ Natalie J Shiff', Deborah M Levy ${ }^{8}$, Elizabeth Stringer ${ }^{3}$, Kimberly Morishita ${ }^{1}$, Rosie Scuccimarri ${ }^{9}$, Lori B Tucker ${ }^{1}$, \\ Rae SM Yeung ${ }^{8}$, Ciaran Duffy ${ }^{5}$, ReACCh-Out Investigators
}

From 21st European Pediatric Rheumatology (PReS) Congress

Belgrade, Serbia. 17-21 September 2014

\section{Introduction}

Accurate description of the risk and nature of flares will help counsel families when JIA is controlled and when considering discontinuing treatment.

\section{Objectives}

To describe the probability and characteristics of flares across JIA categories in an inception cohort of Canadian children treated with a contemporary approach.

\section{Methods}

We studied children diagnosed with JIA between 2005 and 2010 who had at least one visit with inactive disease while being prospectively followed in the Research in Arthritis in Canadian Children emphasizing Outcomes (ReACChOut) cohort. They received usual pediatric rheumatology care at 16 Canadian centres. Flare was defined as any recurrence of disease manifestations after attaining inactive disease (no active joints, no extraarticular manifestations and a physician global assessment $<10 \mathrm{~mm}$ ). Flares were considered major if they required re-initiation or intensification (a new drug was started) of anti-rheumatic treatment. Risk of flare was calculated with Kaplan-Meier survival methods starting at the time of attainment of inactive disease, and at the time of discontinuing all treatment.

\section{Results}

Of 1492 children recruited in ReACCh-Out, 1128 had at least one visit with inactive disease. Median follow-up was 24 months (IQR 12, 39) after attaining inactive disease. A total of 1,179 flares were observed in 532 patients; $55 \%$ of all flares were major flares. The cumulative probability of flare was $25 \%, 42 \%$ and $60 \%$ within 6,12 and 24 months after attaining inactive disease, respectively. By 24 months the risk varied from $49 \%$ for systemic JIA to $72 \%$ for

Table 1 Cumulative probability of flare within 6 and 12 months of stopping treatment

\begin{tabular}{|c|c|c|c|c|c|}
\hline \multirow[t]{2}{*}{ JIA category } & \multirow[t]{2}{*}{ Subjects stopping treatment / total } & \multicolumn{2}{|c|}{ Risk within 6 months (\%) } & \multicolumn{2}{|c|}{ Risk within 12 months (\%) } \\
\hline & & Any flare & Major flare & Any flare & Major flare \\
\hline Systemic arthritis & $37 / 66$ & 11 & 3 & 11 & 3 \\
\hline Psoriatic arthritis & $44 / 75$ & 12 & 12 & 15 & 15 \\
\hline Oligoarthritis & $318 / 481$ & 15 & 12 & 32 & 26 \\
\hline Undifferentiated arthritis & $60 / 111$ & 24 & 13 & 28 & 18 \\
\hline Enthesitis-related arthritis & $77 / 152$ & 29 & 21 & 45 & 33 \\
\hline RF-negative polyarthritis & $85 / 209$ & 25 & 20 & 45 & 40 \\
\hline RF-positive polyarthritis & $4 / 34$ & - & - & - & - \\
\hline
\end{tabular}

${ }^{1} \mathrm{U}$ of British Columbia, Vancouver, Canada

Full list of author information is available at the end of the article 
RF-positive polyarthritis. 625 patients discontinued all treatment. The probability of flares after stopping treatment is shown in the Table (except for RF-positive polyarthritis because only 4 subjects discontinued treatment). Table 1

\section{Conclusion}

Flares after attaining inactive disease were common in this JIA cohort, and the risk was lowest for systemic JIA and highest for RF-positive polyarthritis. Flares after stopping treatment were uncommon in systemic JIA, but occurred in up to $45 \%$ of children within one year in other JIA categories. About half the flares required intensification or re-initiation of treatment.

\section{Disclosure of interest}

None declared.

\section{Authors' details}

${ }^{1} \mathrm{U}$ of British Columbia, Vancouver, Canada. ${ }^{2} \mathrm{U}$ of Manitoba, Winnipeg, Canada. ${ }^{3}$ Dalhousie University, Halifax, Canada. ${ }^{4} \mathrm{U}$ de Sherbrooke,

Sherbrooke, Canada. ${ }^{5} \mathrm{U}$ of Ottawa, Ottawa, Canada. ${ }^{6}$ Western University, London, Canada. ${ }^{7} \mathrm{U}$ of Saskatchewan, Saskatoon, Canada. ${ }^{8} \mathrm{U}$ of Toronto,

Toronto, Canada. ${ }^{9}$ McGill University, Montreal, Canada.

Published: 17 September 2014
Submit your next manuscript to BioMed Central and take full advantage of:

- Convenient online submission

- Thorough peer review

- No space constraints or color figure charges

- Immediate publication on acceptance

- Inclusion in PubMed, CAS, Scopus and Google Scholar

- Research which is freely available for redistribution

Submit your manuscript at www.biomedcentral.com/submit 